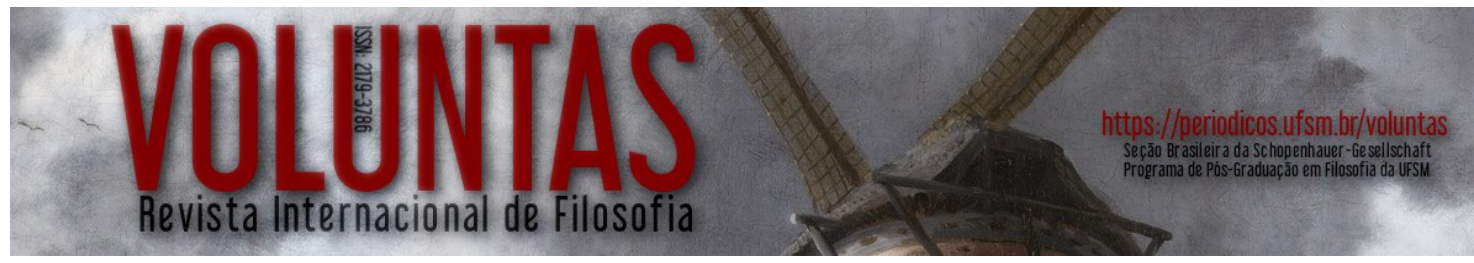

\title{
O que se coloca no lugar da verdade
}

\author{
What stands in the place of truth
}

\author{
Eduardo Ribeiro da Fonseca \\ Professor do Departamento de Filosofia e do Programa de Pós-Graduação em Filosofia \\ da Pontifícia Universidade Católica do Paraná (PUCPR). \\ E-mail: eduardorfonseca@uol.com.br
}

Resumo: Este artigo procura situar Schopenhauer em relação ao problema da verdade, já que ele pode ser tomado, de acordo com Nietzsche, como exemplo e inspiração para aqueles que se dedicam à Filosofia, mediante o que o filósofo de Frankfurt entendia como sendo o papel do filósofo, isto é, aquele que busca a verdade até mesmo no fundo dos poços escuros da loucura e do infortúnio, que tenta decifrar o enigma do mundo e da humanidade e que medita sobre o papel crítico da filosofia no âmbito da cultura.

Palavras-chave: Verdade; Existência; Humanidade; Cultura.

Abstract: This paper seeks to situate Schopenhauer in relation to the problem of truth, since it can be taken, according to Nietzsche, as example and inspiration for those who dedicate themselves to Philosophy, through which the philosopher of Frankfurt understood as the paper of the philosopher, that is, one who seeks the truth even in the depths of the dark wells of madness and misfortune, who tries to decipher the enigma of the world and of humanity and who meditates on the critical role of philosophy in the field of culture.

Keywords: Truth; Existence; Humanity; Culture.

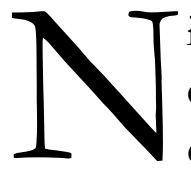
ietzsche escreve que Schopenhauer aceitou a descomunal tarefa de destruir a mentira e trazer à luz tudo o que é falso nas coisas. Podemos entender, com Nietzsche, que aquele que desperta para a contemplação da verdade pode ser visto como uma pessoa que finalmente começasse a acordar para o dia. Desse honesto esforço na direção da verdade, tomada como estrela-guia, resta a imagem de filósofo que inspirou Nietzsche como sendo um educador no sentido próprio, pelo trabalho que fez em si mesmo e tomado como exemplo de postura frente ao objeto do conhecimento. No esforço da verdade, Schopenhauer teria se colocado audaciosamente em oposição ao convencionalismo e aos sistemas de ilusão que alicerçam castelos nas nuvens colocados no lugar do conhecimento ${ }^{1}$. É essa imagem de um educador no sentido próprio o que nos inspira agora como objeto de reflexão, nessa época em que a verdade é aviltada por

\footnotetext{
${ }^{1}$ NIETZSCHE, F. Considerações Extemporâneas: Schopenhauer como educador, p. 75.
} 
"revisionismos" que a colocam nos âmbitos das meras fábulas e narrativas, enquanto Schopenhauer nos indica, pelo contrário, que o mundo possui significado moral. Para ele, há também um conhecimento intuitivo que de certa forma corresponde ao mundo, ainda que só se possa obter e exprimir a totalidade dessa verdade de modo limitado, através de aproximações, analogias, conceitos heurísticos, metáforas. Se há uma educação, é uma educação para a decifração do enigma que representam o mundo, a vida e nós mesmos, esforço honesto e integrador, na medida em que é considerado a partir do valor da intuição e da compaixão e, consequentemente, da negação do egoísmo e do filisteísmo erudito.

Schopenhauer pode ser considerado, com justiça, um filósofo de combate, alguém que gostava de uma disputa, que amava ter inimigos, como sugeria jocosamente Nietzsche. Mas, de fato, ao ressaltarmos a belicosidade como característica de sua personalidade podemos perder de vista certos valores que o próprio Nietzsche, em épocas diferentes também viu no educador. O autor das Extemporâneas (1874) considera Schopenhauer aquele que percebe os sintomas de uma "total extirpação e erradicação da cultura"2.

De fato, o autor de Sobre a filosofia universitária (1851) tinha uma ideia bastante precisa sobre o que seria a "verdadeira filosofia" e sobre o "papel do filósofo". Para chegar ao estatuto da filosofia ele reflete sobre sua própria atividade e sobre o lugar que, como filósofo, ocupa em sua época. Para ele, a marca do discurso filosófico é a sua incompletude. À diferença da matemática e das ciências empíricas, a filosofia não é um saber pronto e acabado ${ }^{3}$.

Disso resulta o problema da transmissão do conhecimento filosófico: é possível ensinar filosofia, mas não é possível ensinar a filosofar. Para Schopenhauer, a primeira tarefa do wirklicher Philosoph é a constituição de um pensamento próprio, o que se contrapõe à recepção passiva de sistemas filosóficos anteriores. Apenas aquele que pensa "por si" pode "iluminar os demais"4. Sem dúvida, esse é um ponto de vista que anula, ao menos parcialmente, a crítica de Freud aos filósofos.

A verdade desinteressada é o único objetivo do filósofo. Deveria afastar um pensador dos desvios obscuros da tendenciosidade. Schopenhauer diz que sua estrelaguia foi "de modo sério" a verdade: "Obviamente não posso escapar dos erros (Feblern) e fraquezas (Schwächen) necessariamente inerentes à minha natureza, como a qualquer outra; entretanto, não as multiplicarei com acomodações indignas"5.

Para o filósofo, a verdade é problemática. Todo ser vivo manifesta um completo interesse pelos seus objetos de desejo, inclusive intelectuais e, por isso, a consciência tende a ser enganadora. De modo correlato, a linguagem é um

\footnotetext{
2 Ibidem, p. 74.

${ }^{3}$ FONSECA, E. Psiquismo e vida: Sobre a noção de "Trieb" nas obras de Freud, Schopenhauer e Nietzsche, p. 26.

4 SCHOPENHAUER, A. P, Sobre a filosofia universitária, p. VIII.

${ }^{5}$ SCHOPENHAUER, A. MVR I, p. 18.
} 
instrumento narcísico. Para que a consciência veja o mundo, é preciso que se abstraia de si mesma: "O leitor sempre me encontrará no ponto de vista da reflexão (Standpunkt der Reflexion), isto é, da deliberação racional, nunca do ponto de vista da inspiração, chamada intuição intelectual (Intellektuelle Anschauung), ou do pensamento absoluto (absolutes Denken), cujos nomes mais corretos são: vazio intelectual (Windbeutelei) e charlatanismo (Scharlatanerei)"6.

Note-se que verdade e reflexão "são conceitos interdependentes, que excluem a noção de um saber absoluto. Para Schopenhauer, isso exige uma volta a Kant, pois, ao contornarem as proibições impostas pela Crítica da raz̧ão pura, os filósofos póskantianos não teriam respeitado os limites do conhecimento especulativo"7.

A exigência de liberdade e verdade no ensino da filosofia é um tema kantiano de 1798, exposto na obra Conflito das faculdades, onde o filósofo caracteriza a filosofia como o lugar do pensamento crítico que se exerce livre e autonomamente. A ela caberia pôr à prova a verdade dos conhecimentos específicos ensinados aos jovens. No tempo de Schopenhauer, em contraste com o desejo de Kant, a faculdade de filosofia está subordinada às demais e aos interesses do Estado e da religião estatal. Se há um conflito, já não se trata de uma luta entre faculdades, mas entre a "filosofia universitária" e a "verdadeira filosofia".

À visão otimista de Kant, que propõe a faculdade de filosofia como lugar do pensamento crítico, contrapõe-se a visão dura de que a instância decisiva é o desejo ligado ao querer humano. O pensamento prático subordina o "professor de filosofia" ao Estado e ao sistema filosófico bem-aceito, o que o faz também conivente com os dogmas e com o poder. Isto impede o florescimento de "verdadeiros filósofos" nas faculdades de filosofia.

Se não é possível achar um filósofo na faculdade de filosofia, como encontrálo? Um importante fator que identifica o "verdadeiro filósofo" é o seu uso da linguagem. Esta é entendida como instrumento da verdade filosófica e como antídoto ao dogma. Ao utilizar os conceitos presentes na linguagem, ela não deve se tornar com isso uma mera abstração intelectual, o que estancaria o processo sempre provisório de generalização dos dados empíricos. O saber filosófico encontra seu limite no "porque" que transcende a experiência. Porém, pode tentar responder "o que é o mundo".

Schopenhauer critica Kant quando este define a filosofia como "ciência que partiria de meros conceitos". Sua crítica mais enfática, no entanto, é contra as abstrações conceituais dos "sofistas" pós-kantianos. Para ele, a fonte da filosofia é a experiência interna e externa, que fixa os limites para o uso da razão. Mas, nesse sentido, não teria sido uma ousadia intelectual tentar decifrar o "enigma do mundo"?

\footnotetext{
"Idem, p. 17. Segundo o tradutor, a noção de "inspiração" se refere à filosofia de Fichte e Schelling, enquanto a noção de "pensamento absoluto" pertence a Hegel.

${ }^{77}$ FONSECA, E. Psiquismo e vida: Sobre a noção de Trieb nas obras de Freud, Schopenhaner e Nietzsche, p. 26.
} 
Em Schopenhauer como educador, terceira das Considerações extemporâneas (1874), Nietzsche elogia Schopenhauer em sua existência como filósofo. Ele foi capaz de fornecer um exemplo e servir como modelo para os que pretendem educar a si mesmos. Como Schopenhauer, Nietzsche também ironiza a filosofia universitária de seu tempo e a erudição desvitalizada dos professores de filosofia. Insiste no papel crítico da filosofia e no seu poder de transformação da ordem estabelecida.

Essa ordem estabelecida se sustenta, em grande medida, no modo como as pessoas são educadas. Essa é uma problemática comum não apenas a Schopenhauer, mas também a Nietzsche. Este constata, com aquele, que o objetivo do sistema educacional alemão do seu tempo é o de formar o homem erudito, o "filisteu da cultura", que se caracteriza por viver "empanturrado de mil impressões de segunda mão". A tarefa do filósofo, pelo contrário, é "chegar a si mesmo": "A história erudita do passado nunca foi ocupação de um filósofo verdadeiro" (einen wahren Philosophen) ${ }^{8}$.

No entanto, todo verdadeiro filósofo, independentemente do modo como tenha sido educado ou como tenha educado a si mesmo, não poderá se livrar do fardo de ter o seu pensamento, que é fruto de sua existência e de sua capacidade para modificar e acrescentar algo à história do pensamento, saqueado e modificado de modo espúrio por falsificadores e manipuladores. Nesse sentido, a visão que Schopenhauer nos apresenta acerca do modo como a obra de Kant é recepcionada pelo Idealismo Alemão é significativa. Ele nos diz que Kant não somente é mal compreendido, mas também perversamente transformado de acordo com as finalidades duvidosas de cabeças de vento que não buscam expor a verdade, mas sim ocultá-la, toda vez que isto for necessário para atingirem uma finalidade prática da vida. Dito em linguagem schopenhaueriana, o intelecto desses filisteus da Filosofia está escravizado pelo desejo e, desse modo, não pode ter a pretensão de uma visão objetiva do mundo, ou da obra de um autor como Kant. Esse erudito, que pode ser tanto um iludido quanto alguém mal-intencionado, ou ambos, espera nas sombras a morte do filósofo, para então se apropriar da sua obra e fazer dela o que bem entende, como um criminoso sequestra a sua vítima para obter determinadas vantagens.

No capítulo dos Complementos de 1844 intitulado "Sobre a necessidade metafísica da humanidade", Schopenhauer menciona que "aqueles que vivem para a filosofia não são apenas muito diferentes daqueles que vivem da filosofia, mas são muito frequentemente seus adversários e ainda seus inimigos ocultos e implacáveis", pois toda realização filosófica genuína e importante "lança também uma grande sombra sobre eles, além de não se adequarem às intenções e limitações de sua corporação [Gilde]" . O filósofo escreve que é por esta razão que eles sempre se esforçam para impedir que essa realização seja devidamente apreciada pelo público. A interpretação

${ }^{8}$ Cf. NIETZSCHE, F. KSA I, p. 416; Obras Incompletas, p. 81.

9 SCHOPENHAUER, A. MVR II, p. 254. 
marcada pelos traços perversos da leitura dos intérpretes vai apresentar um filósofo muito diferente daquele pensador original que se apresentaria melhor ao leitor sem esse intermediário sem escrúpulos que utiliza a filosofia como uma moeda para conquistar posições ou manter vantagens. Schopenhauer também diz que "os meios costumeiros para fazer isso, de acordo com a época e as circunstâncias em cada caso, consistem em ocultar, encobrir, dissimular, ignorar, segregar, ou então negar, rebaixar, censurar, caluniar, falsificar, bem como também denunciar e perseguir" ${ }^{10}$. Nesse sentido, "mais de uma grande cabeça teve que se arrastar pela vida, sem reconhecimento e sem fôlego, desonrada, sem recompensas, até que finalmente, depois da sua morte, o mundo lhe fez justiça e aos seus perseguidores"11. No desenrolar desse processo, justamente os falsificadores e caluniadores atingem seu objetivo, obtêm o prestígio que é negado ao pensador original, "vivendo da [von] filosofia, com sua mulher e filhos, enquanto o verdadeiro filósofo vive para [für] ela"12. Quando o filósofo morre, no entanto, as coisas mudam. "A nova geração se apropria do legado de suas realizações, podando-o e fazendo-o descer aos seus próprios padrões para então viver à custa dele"13. Essa relação de caráter algo pessimista com a posteridade, ou seja, conosco, que somos seus intérpretes e comentadores, é importante objeto de reflexão para aquele que se pretende um estudioso deste filósofo: a ideia de falsificação. O filisteu da filosofia, o cabeça oca filosófico utiliza o filósofo ora como um estofo para o seu crânio vazio, ora como um elmo, ou seja, uma cabeça emprestada tanto para se defender de ataques, quanto para distribuir cabeçadas em busca de vantagens e posições, isto é, para satisfazer uma vontade mesquinha, e, em outro sentido, verdadeiramente negar a verdade.

Se o problema relacionado à autenticidade do pensamento é inerente ao filosofar e, no caso particular da filosofia de Schopenhauer, especialmente no que concerne aos argumentos do capítulo XIX dos Complementos de $1844^{14}$, tenhamos que admitir que ao fundo do pensar consciente exista um querer inconsciente que produz falsificações involuntárias, há também a falsificação proposital, que não está sob recalque, para utilizar uma linguagem que me é cara, a da psicanálise. Trata-se de perversidade. Resumindo, se a verdade é negada, por um lado, devido ao apego à existência, não sendo nesse caso resultado de reflexão ou de escolha, mas da preponderância da vontade inconsciente sobre a percepção e sobre os pensamentos, há também casos em que a primazia da vontade sobre a consciência é admitida na própria consciência e esta faz cálculos, medita sem descanso e sem consideração pela verdade, tendo como único objetivo a satisfação descarada dos próprios desejos,

\footnotetext{
${ }^{10}$ Ibidem.

11 Ibidem.

12 Ibidem.

13 Ibidem.

${ }^{14}$ Idem, p. 307.
}

Voluntas: Revista Internacional de Filosofia - periodicos.ufsm.br/voluntas - Santa Maria - Vol. 9, n. 1, jan.-jun. 2018, pp. 68-78 
desconsiderando completamente as outras pessoas e a percepção objetiva dos fatos, que, no entanto, não ignora, sendo capaz de manipulação, desconsideração, apropriação, deturpação e outras coisas semelhantes. Enquanto a negação da verdade, no primeiro caso, dá-se por um mecanismo inconsciente, que simplesmente nega ou então rechaça com violência a verdade, no outro, há a explicitação de um mecanismo de negação perversa, tal como o considerado por Freud em sua obra. No caso do homem perverso, o núcleo de sua natureza íntima aparece exposto em sua consciência. Ele não está mais oculto por trás da cortina da consciência, não se esconde dessa consciência, mas antes se afirma na própria consciência sem a consideração de um possível significado moral para as nossas ações humanas. A Gewissen, nesse caso, a consciência moral, não é desconsiderada, mas é exterior ao sujeito. A lei não é um céu estrelado dentro do perverso, mas apenas fora dele, e a realidade psíquica não está sob recalque, já que o perverso sabe que existe realidade psíquica e faz o papel de ilusionista não para o seu próprio intelecto, mas sim para o dos outros. Se no homem comum a Verneinung é o índice negativo que marca justamente o reconhecimento do inconsciente, no perverso se apresenta diante de nós uma forma de negativa, a Verlengnung, que é marcadamente uma tentativa de ocultar propositalmente a verdade, isto é, a verdade que é negada está presente na consciência e não sob um Verdrängung, isto é, não está oculto sob a repressão.

Nesse último sentido, precisamos considerar que o que ocorre no âmbito do indivíduo determinado também acontece no âmbito da sociedade. Também no íntimo do indivíduo coletivo, expressão meramente metafórica, há uma reação psicológica negativa à franqueza, e ocorre uma Spaltung, uma divisão, um fracionamento, uma fissão, um cisma da consciência social em relação à sua verdade mais íntima. Em qualquer caso, trata-se sempre de uma forma de defesa contra a verdade mais branda, mais intensa, violenta, ou perversa, e isso se expressa em alemão através de diversos vocábulos que expõem as relações da consciência com a verdade desagradável ou com a mentira agradável ou satisfatória de alguma maneira.

Trocando em miúdos, a primeira forma da negativa que mencionei é a Verneinung (negação [de uma ideia consciente ou da representação sob repressão], repúdio, dizer não, negativa, denegação). Outras formas são a Verwerfung (rejeição [da representação e do afeto sob repressão], desaprovação, condenação, forclusão [como algo que não pertence ao sujeito]), e Verleugnung (renegação, entendida como negação [do afeto ligado à representação sob repressão]; assim, define-se como uma negativa que repudia a própria natureza ou nega o que já se conhece e que, por isso, aplica-se bem à perversão, como vemos no artigo de Freud sobre o fetichismo).

Todos esses vocábulos são utilizados por Schopenhauer, não em um sentido técnico como em Freud, mas de modo razoavelmente preciso, restando talvez uma dificuldade conceitual no sentido de determinar até que ponto eles se referem ou não a estruturas psicológicas específicas e de que forma, ainda que esquematicamente, 
possamos falar, sim, de um ponto de vista estrutural, em termos de neurose (Verneinung), psicose (Verwerfung, Verleugnung) e perversão (Verleugnung). Mas para nós, nesta apresentação, isso não faz tanta diferença, embora desperte nosso interesse, pois todos estes vocábulos reforçam a ideia mencionada por nós de inadmissibilidade, de mal-estar em relação a determinados afetos e representações consideradas incompatíveis e em oposição a uma Bejahung (afirmação do afeto ou da representação a ele ligada), o que, em suma, está na base da clínica psicanalítica.

Em Schopenhauer a noção de Verneinung des Willens (negação da vontade) é crucial para a compreensão adequada de sua ética. A negação é vista por ele como resultado final do autoconhecimento da vontade no mundo, como um desencanto consigo mesma, enquanto a Bejahung é considerada algo natural e a própria característica de nossa individuação, pois até mesmo o suicídio é considerado por Schopenhauer como um derradeiro ato de afirmação da vontade. Se, para o filósofo, o autoconhecimento da vontade é aquilo em que consiste o próprio mundo, a Verneinung é algo que só pode ser expresso negativamente, já que somos a própria vontade de viver nesse percurso, ou, dito de outro modo, a afirmação do querer-viver. Nesse sentido, a viragem do querer-viver no âmbito individual só pode acontecer "através de uma violência dolorosa contra si mesmo"15. Em O mundo como vontade e representação, de 1819, e nos seus Ergänzungen (Complementos, de 1844) ${ }^{16}$ são abundantes os exemplos de uso do vocábulo. O uso comum do termo no idioma alemão está representado, por exemplo, na frase: "Verneinung, Aufhebung, Wendung des Willens ist auch Aufhebung und Verschwinden der Welt, seines Spiegels" (Negação, supressão, reviravolta da vontade é também supressão e desaparecimento do mundo, seu espelho) ${ }^{17}$. A negação em sentido próprio é, na sua metafísica, um profundo desencanto da vontade consigo mesma, cujo efeito pode ser uma autossupressão, enquanto a atitude comum de negação aparece para o filósofo como uma afirmação disfarçada ou codificada. $\mathrm{O}$ significado como "denegação" ou negar rebatendo algo com um "não", e, através disso, podendo permitir o acesso à consciência de um conteúdo inconscientemente afirmado, mas não reconhecido pela consciência, não é expresso diretamente pelo filósofo, mas a sua ideia sim. Podemos encontrar esses pensamentos na sua Metaphysike der Geschlechtsliebe (Metafísica do amor sexual, de 1844), no contexto das reflexões éticas do quarto livro, já que a sexualidade é incessantemente vivida pelas pessoas e, concomitantemente, recoberta por um véu de linguagem e distorcida por nossas ações comuns como se fosse coisa sem importância, embora, na prática, a importância fundamental que atribuímos à nossa vida afetiva demonstre justamente o contrário ${ }^{18}$.

${ }^{15}$ SCHOPENHAUER, A. MVR II, p. 289.

16 Trata-se da segunda edição de $O$ mundo como vontade e representação acompanhada de Complementos, como eu chamo, ou Suplementos, como dizem outros tradutores.

${ }^{17}$ SCHOPENHAUER, A. MVR I, p. 485.

${ }^{18}$ Cf. SCHOPENHAUER, A. MVR II, p. 243.

Voluntas: Revista Internacional de Filosofia - periodicos.ufsm.br/voluntas - Santa Maria - Vol. 9, n. 1, jan.-jun. 2018, pp. 68-78 
Já os vocábulos Verleugnung ${ }^{19}$ e Verwerfung são também usados de forma recorrente na obra de Schopenhauer, de acordo com critérios razoavelmente semelhantes aos de Freud, ainda que sem o aspecto técnico e clínico que estão sempre envolvidos nas concepções freudianas.

A primeira palavra é utilizada, por exemplo, no $\ 163$ dos Parerga e Paralipomena ${ }^{20}$ (1851) para falar da gänzliche Verleugnung seiner selbst (inteira renúncia a si mesmo) ${ }^{21}$. O termo é usado também para falar da associação entre hipocrisia e cortesia na sociedade, quando o filósofo de Frankfurt menciona, no parágrafo 14 de Sobre o fundamento da moral, o repúdio violento e meramente convencional do egoísmo por parte do próprio egoísta, como ele diz, uma folha de parreira colocada sobre o egoísmo, hipocrisia, para usar o termo correto, como se o egoísta não tivesse nada a ver com o assunto: "Die Höflichkeit nämlich ist die konventionelle und systematische Verleugnung des Egoismus" (A cortesia é, nomeadamente, o repúdio convencional e sistemático do egoísmo) ${ }^{22}$. A professora Maria Lúcia Cacciola utiliza "cordialidade" e "negação", na página 116 de sua tradução. Nesse contexto, apenas a compaixão é de forma autêntica um repúdio (Verleugnung) do egoísmo e da maldade ${ }^{23}$. Em Sobre a filosofia universitária Schopenhauer fala também do "repúdio [Verleugnung] de toda consciência literária" por parte do "filisteu universitário"24. Em seu texto Sobre a doutrina do Direito e politica, dos Parerga e Paralipomena, \127, ele fala de um "Verlengnung des Rechtlichkeit" ["repúdio da retidão"] das autoridades políticas influenciando perniciosamente o povo ${ }^{25}$, e, através disso, Schopenhauer expressa seu profundo desagrado para com o abuso de poder econômico dos norte-americanos contra as nações vizinhas, especialmente a guerra de conquista de territórios mexicanos e também condena veementemente a escravidão, os linchamentos, o absurdo dos duelos sangrentos e do utilitarismo mesquinho ${ }^{26}$.

Por outro lado, Verwerfung é um termo usado, entre outras coisas, para expressar a rejeição do público leitor para com o próprio filósofo e sua obra, o que nos interessa sobremaneira aqui. Ele escreve em $O s$ dois problemas fundamentais da ética, de 1841, que a Sociedade Real Dinamarquesa, que não o premiou, apesar de ser o único

\footnotetext{
${ }^{19}$ Palavra pela qual Schopenhauer traduz o termo latino abnegatio, na expressão abnegatio sui ipsius (negação de si mesmo) e que traduzi nos Complementos (SCHOPENHAUER, A. MVR II, v. 2, p. 338) como "negação" na expressão "autonegação" [Selbstverlängnung].

20 Segundo o tradutor e pesquisador Flamarion Caldeira Ramos, a expressão grega pode ser traduzida aproximadamente como Ornatos e Complementos (Cf. SCHOPENHAUER, A. Sobre a Ética, p. 5).

${ }^{21}$ SCHOPENHAUER, A. P, p. 340. Utilizo a tradução de Flamarion Caldeira Ramos: SCHOPENHAUER, A. Sobre a ética, p. 175.

22 SCHOPENHAUER, A. M, p. 668.

${ }^{23}$ Idem, p. 727.

24 SCHOPENHAUER, A. P, p. 174.

${ }^{25}$ Flamarion Caldeira Ramos, em sua tradução dos escritos Sobre a Ética (p. 101) emprega nesse mesmo caso a expressão "negação da integridade", uma variação correta que menciono aqui para evidenciar justamente a riqueza de possibilidades de tradução e os diferentes contextos que precisam ser considerados quando se traduz. 26 SCHOPENHAUER, A. P, p. 277.
} 
concorrente de uma premiação, se agarrou ao que pôde para poder "rechaçar" o seu trabalho (zur Verwerfung meiner Arbeit) ${ }^{27}$. No Tomo I, de 1819, de $O$ mundo como vontade e representação, ele escreve: "den wabren Grund zur Verwerfung des Selbstmorde" ("O verdadeiro fundamento para o repúdio ao suicídio") ${ }^{28}$. No $\int 41$ da mesma obra, ele comenta sobre Platão: "seiner Geringschätzung und Verwerfung der Kunst, besonders der Poesie" [seu desprezo e repúdio em relação à arte, especialmente à poesia] ${ }^{29}$. Outro uso que corresponde à noção de repúdio ou condenação está em Sobre a vontade na natureza, de 1836: "tal repúdio [Verwerfung] é evidentemente precipitado"30 e, na página seguinte: "repúdio a priori de tais acontecimentos" 31 . Nos Aforismos para a sabedoria de vida, de 1851, ele fala de "Verwerfung aller Genüsse" ("repúdio de todos os prazeres") 32. Enfim, são muitos os usos de acordo com a linguagem comum do idioma alemão, exatamente como Freud procurava fazer, apesar de seu objetivo clínico.

No contexto desses vocábulos da língua alemã, e considerando a reação do público específico que discute a obra de Schopenhauer, há uma reação matiz̧ada, na qual o nível de rejeição varia, há maior ou menor admissibilidade ou repúdio, maior ou menor intensidade de reação. Mas, de um modo geral, sempre ocorre uma rejeição mais ou menos violenta para a qual se deve estar preparado, especialmente quando o assunto é a melindrosa sexualidade humana. A base da negação está relacionada à agressividade da verdade, que produz uma ruptura dos padrões culturais hipócritas, astuciosos e, portanto, perversos das estruturas de dominação.

Schopenhauer nos serve como exemplo, como diz Nietzsche em seu Schopenhauer como educador, e também em A Gaia ciência (Os seguidores de Schopenhauer), pelo seu "duro senso dos fatos" 33 , que é e não é um pessimismo, já que a verdade pode ser vista como um pessimismo, mas também tem a sua face redentora, o seu consolo, pois permite que as estruturas sociais possam, ao serem reconhecidas de modo autêntico, serem também modificadas. O grande risco é que ocorra, como ocorre no Brasil de hoje, um retrocesso na direção da Verlengnung, após evidentes conquistas sociais no sentido do desenvolvimento humano, da recuperação da dignidade das pessoas, e da diminuição da desigualdade e da violência contra a maioria, e passemos não apenas a nos deparar, mas a sermos verdadeiramente captados novamente para o interior do mundo escravocrata de nossa origem como colônia de exploração. Nesse sentido, o pessimismo de Schopenhauer pode ser um santo remédio. Sabemos que o teatro da Humanidade se baseia na recorrência, que

27 SCHOPENHAUER, A. M, p. 445. Na tradução espanhola de Pilar López de Santa María consta "rechazar mi trabajo" (Madrid: Siglo XXI, p. 13).

28 SCHOPENHAUER, A. MVR I, p. 108.

${ }^{29}$ Idem, p. 250.

30 SCHOPENHAUER, A. N, p. 391.

31 Idem, p. 392. A tradução de Gabriel Valladão Silva utiliza o termo "condenação".

32 SCHOPENHAUER, A. P, p. 451. Em sua tradução dos Aforismos, Jair Barboza utiliza "rejeição".

${ }^{33}$ NIETZSCHE, F. A Gaia Ciência, p. 123. 
mudam os atores e os cenários, mas a peça é sempre a mesma. Cabe-nos uma posição frente ao problema filosófico (mas também prático) a que essas reflexões aqui apresentadas nos levam. Precisamos saber, portanto, qual o nosso papel nessa peça, a que tipo de atitude corresponde melhor o nosso caráter individual, se a uma postura compassiva frente à nossa Humanidade comum, ou se vamos nos comportar de modo egoísta, perverso e maligno! Todos aqui sabem pelo que estamos passando. E no coração de cada um essas palavras calarão de um jeito. Precisamos também, de qualquer modo, de acordo com nossas limitações individuais, saber o que colocamos no lugar da verdade.

\section{Referências bibliográficas}

CACCIOLA, Maria Lúcia Mello e Oliveira. Schopenhauer e a questão do dogmatismo. São Paulo: Edusp, 1994.

NIETZSCHE, F. Considerações Extemporâneas: Schopenhauer como educador. In: Obras Incompletas. Trad. Rubens Rodrigues Torres Filho. São Paulo: Abril Cultural, 1978.

NIETZSCHE, F. A Gaia Ciência. São Paulo: Companhia das Letras, 2001.

SCHOPENHAUER, A. Sämtliche Werke. Hrsg. von Wolfgang Frhr. Löhneysen. Frankfurt, 1986, 5 vols.

SCHOPENHAUER, A. Die Welt als Wille und Vorstellung. Ergänzungen. In: Sämtliche Werke.

SCHOPENHAUER, A. Parerga und Paralipomena. In: Sämtliche Werke.

SCHOPENHAUER, A. Die Beiden Grundprobleme der Ethik, I. In: Sämtliche Werke.

SCHOPENHAUER, A. Über die Freiheit des Willens / Os dois problemas fundamentais da ética, Vol. I. In: Sämtliche Werke.

SCHOPENHAUER, A. Sobre o fundamento da moral. Trad. Maria Lúcia Mello e Oliveira Cacciola. São Paulo: Martins Fontes, 2001.

SCHOPENHAUER, A. Sobre a filosofia universitária. Trad. Maria Lúcia Mello e Oliveira Cacciola e Márcio Suzuki. São Paulo: Martins Fontes, 2001.

SCHOPENHAUER, A. Aforismos para a sabedoria de vida. Trad. Jair Barboza. São Paulo: Martins Fontes, 2002.

SCHOPENHAUER, A. O mundo como vontade e como representação. Tomo I. Trad. Jair Barboza. São Paulo: Unesp, 2005.

SCHOPENHAUER, A. Sobre a Ética. Trad. Flamarion C. Ramos. São Paulo: Hedra, 2012. 
SCHOPENHAUER, A. Sobre a vontade na natureza. Trad. Gabriel Valladão Silva. Porto Alegre: L\&PM, 2013.

SCHOPENHAUER, A. O mundo como vontade e representação: Complementos. Tomo II. 2 vols. Trad. Eduardo Ribeiro da Fonseca. Curitiba: Editora UFPR, 2014.

Recebido: $14 / 05 / 18$

Received: $05 / 14 / 18$

Aprovado: $11 / 06 / 18$

Approved: 06/11/18 